\title{
Acute Appendicitis and Its Complications: Diagnostic Challenge and Treatment, Literature Review
}

\author{
Palmieri Luna Alfonso ${ }^{1 *}$, Carrascal Castillo Edgar Alfredo², Garcias Díaz Luis Alfonso², Salcedo Rodríguez Jhan \\ Carlos $^{2}$, Zapa Pineda Silvio Andrés ${ }^{2}$, Palmieri Hernandez Adriana Maria ${ }^{3}$ and Hernandez Amin Luz Adriana ${ }^{4}$
}

${ }^{1}$ Especialista Cirugía General, Laparoscopia, Capítulo Cirugía Minimally Invasive (Colombian Association of Surgery) Santa María Clinic, Professor of the Sucre University Medicine Program, Colombia

${ }^{2}$ Medicine Students VI semester of the University of Sucre, Colombia

${ }^{3}$ Semester Student of the Universidad del Norte School of Medicine, Colombia

${ }^{4}$ Master in Nursing, Teaching Coordinator Teaching Service Relationship, Colombia

Submission: February 22, 2021; Published: March 02, 2021

*Corresponding author: Alfonso Palmieri Luna, Physician, specialist in General Surgery and Laparoscopy, member of the Colombian Association of Surgery (ACC), Latin American Federation of Surgery (FELAC). Surgeon of the Santa María Clinic; Professor of Chair, subject Adult Health II, Medicine Program, University of Sucre, Carrera 43 \# 25A-04 (Barrio Venecia vieja), Sincelejo, Sucre, Colombia

\section{Abstract}

We present the clinical case of a 54-year-old female patient, who came to the emergency department for abdominal pain of 2 days of evolution, predominantly mesogastric and radiating to the right iliac fossa, accompanied by nausea and vomiting, does not refer fever. The clinical and paraclinical symptoms are suggestive of acute appendicitis. With Alvarado's criteria with a high probability of acute appendicitis, she motivates herself and prepares for appendectomy, finding retroileal appendicular plastron. In the immediate postoperative period, complications inherent to the procedure arise: medically managed retroileal hematoma x 72 hours, decrease in hemoglobin levels, which requires a transfusion of compatible packed red blood cells, significant retroileal hematoma drainage is performed with infiltration in the ileum walls Cecal, bizarre evolution, torpid, with vomiting, abdominal distention, absence of stools and flatus on postoperative day 10, an Abdomen Rx is performed where they report air-fluid levels, Contrasting Computerized Axial Tomography of the abdomen reports narrow ileus cecal union, which is why it is motivated for Laparotomy explorer, finding stenosis of the ileo cecal segment due to stenosis, distortion of the segment, performing a right hemicolectomy and ileotransverse anastomosis, good evolution in the Intensive Care Unit until the 8th day when she presented leakage of intestinal contents through the penrose drain, quantifying $\mathrm{m}$ As of $500 \mathrm{cc}$ a day, classifying high-output fistula, signs of abdominal sepsis, it is motivated for exploratory relaparotomy, with a frozen abdominal cavity, by multiple peritoneal adhesions, peritonitis, managing to identify the fistula of the anastomosis, friable tissue, performing drainage of localized peritonitis of the right hemiabdomen, ileostomy plus transverse colostomy, subsequently suffers alkaline burn at the operative site, despite handling with the colotomy kit isolating the ostomy from the skin, enters into hydro-electrolyte imbalance with severe hypokalemia, managing it with Parenteral replacement of potassium, until stabilizing and overcoming abdominal sepsis, being discharged after the 2nd month of hospitalization.

Keywords: Appendicitis; Complications; Hemicolectomy; Ileostomy; Colostomy

\section{Introduction}

Acute appendicitis is the main cause of surgical care in emergency centers around the world, with a diagnosis percentage of $26.7 \%$ to $60.6 \%$, and within this percentage, 3.7 to $28.6 \%$ represent appendicitis with perforations [1-3]. Once the pathology of acute appendicitis is diagnosed, an appendectomy should be performed, therefore the results that this surgical act can trigger are closely related to the precociousness of the latter [4-6]. It is also related to the stage of the appendicular process [5-7].
In the context of pathologies like this, proceeding with surgery is indicated in confirmed cases and also in cases where it cannot be excluded from differential diagnoses, due to mortality and morbidity in these patients when undergoing laparotomy conventional or laparoscopic, are appreciably less than those that would occur in the patient if his appendicitis is allowed to evolve to more serious stages (gangrenous and perforated) and the risk is much more increased, if it is a patient who is at the extremes of life $[7,8]$. 
Following the same order of ideas, the complications that can occur after the resolution of an acute appendicitis is not uncommon, despite the many technological advances and procedures in surgery, anesthesiology and resuscitation, which seek to reduce the trauma caused to the maximum for a surgical act $[9,10]$. Some of the complications of this are mentioned: Intra or postoperative bleeding that warrant reoperations, hematomas, seromas, from the surgical wound due to poor hemostasis, intra-abdominal abscesses, hemorrhage, phlebitis, intestinal obstruction, stercoracic fistulas, sepsis, septic shock, evisceration and eventration [11].

\section{Clinical Case}

Female patient, 54 years old, from Sincelejo - Sucre; from and resident in Sincelejo - Sucre; widow, Catholic, beneficiary of the subsidized scheme (Mutual Ser). Emergency consultation on September 20, 2016 with a clinical picture of approximately 2 days of evolution of distension Abdominal pain and pain predominantly in the mesogastrium radiating to the right iliac fossa that worsens in the last hours. Associated with nausea and vomiting. Denies the presence of fever.

The patient has no previous pathological history. There is no relevant personal and / or family history. On physical examination, the patient was found to be in a fair general and nutritional condition with allergic facies. Vital signs: Pulse: 78 beats per minute; RT: 110/80 mmHg; FR: 19 breaths per minute. T: $38^{\circ} \mathrm{C}$. Normocephalic patient, anicteric sclera, dry oral mucosa, non-congestive oropharynx, mobile neck, symmetrical, not painful, no masses or lymph nodes palpable, thorax symmetric, expandable; no pulls, rhythmic heart sounds without murmurs, lungs with preserved vesicular murmur, no overgrowths, flat, soft, depressible abdo- men, 3 per minute peristalsis, with tenderness at the level of the right iliac fossa, doubtful Blumberg's sign, positive psoas. No signs of peritoneal irritation at the time of abdominal examination. Neurologically, alert, conscious, without motor or sensory deficit, without motor or sensory deficit. Glasgow 15/15 General surgery orders paraclinics showing: hemoglobin $12.4 \mathrm{gr} / \mathrm{dl}$; leukocyte count 7,700; platelets 288,000; serum chlorine level of $108 \mathrm{mEq}$ / l; serum potassium k $3.4 \mathrm{mEq} / \mathrm{L}$; serum sodium level of 145 $\mathrm{mEq} / \mathrm{l}$.

The ultrasound reported September 20, 2016: gallbladder with stones of 8 and $12 \mathrm{~mm}$ with posterior shadow, wall not thickened, common bile duct not dilated. Pancreas, head, body and tail normal. Kidneys, adrenals and spleen without alterations. Abdominal vessels of normal caliber, not abdominal masses or collections. Normal urinary bladder. 15 x $90 \mathrm{~mm}$ hypoechoic tubular image in the right iliac fossa. No free liquid. Colic distension with abundant gas. Alvarado's criteria with high probability of acute appendicitis, for which appendectomy, lysis of peritoneal adhesions, peritoneal lavage, transfer to the Intensive Care Unit, for sepsis management is motivated.

The patient develops a series of complications in which the following stand out: A diagnostic postsurgical hematoma in an abdominal ultrasound $09 / 23 / 2016$ that reports cholelithiasis and a residual hematoma, after which a laparotomy is scheduled in which a retrocecal and mesoappendix hematoma was found as well as the distal ileum meso and adhesions, epiploic appendages of the plastron which were ligated with silk in this case, management was adhesion lysis, reexploration + drainage of postsurgical hematoma, hemostasis of mesenteric vessels and surgical lavage.

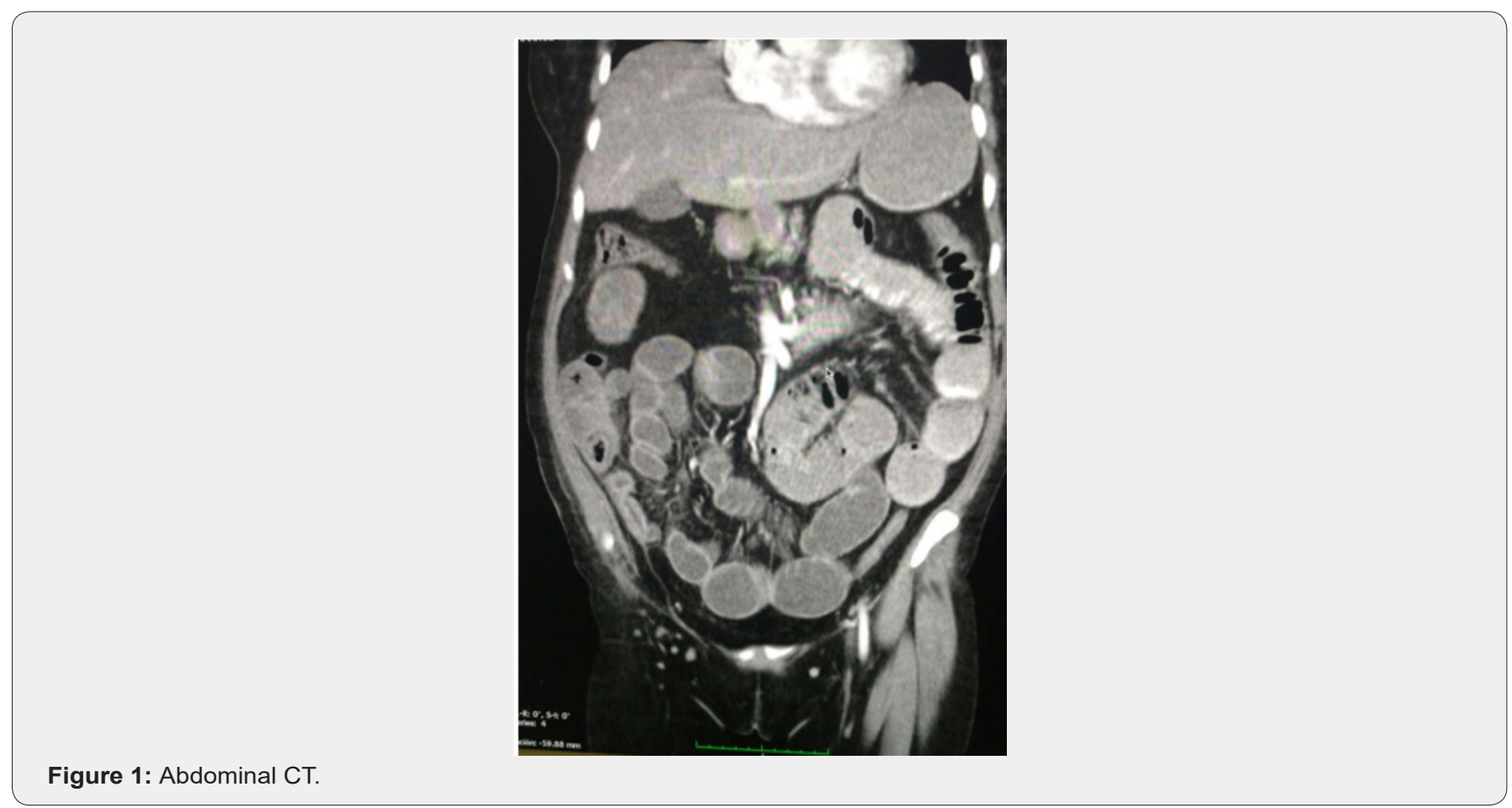


7 days after the postoperative surgery on $10 / 10 / 2016$, the patient was taken to surgery for an exploratory laparotomy (right hemicolectomy due to retrocecal obstructive plastron-ileocecal valve). This intestinal obstruction was reported in the absence of peristalsis, which is why A contrasted abdominal CT was requested, which was performed on 10/04/2016 (Figure 1), which reported evidence of a decrease in the intestinal lumen at the distal ileum, with dilation of the thin loops. No contrast medium passed into the colon; transverse ileus anastomosis; lysis of peritoneal ad- hesions is performed; surgical lavage by laparotomy (Figure 2); It was followed as a procedure due to the leakage of intestinal juice through the penrose drain in a moderate amount, difficult to quantify associated with distension and generalized abdominal pain for 8 hours, serous discharge from a moderate amount of surgical wound. Flatus and stools ++ , denies fever, chills.

The patient presented a final complication, a burn secondary to exposure to alkaline substances of intestinal juices caused by the ileostomy (Figure 3).

Note the obstruction (Circle) and distal and proximal dilation.

Intestinal distention (Arrow).

Figure 2: Intestinal obstruction, stricture.
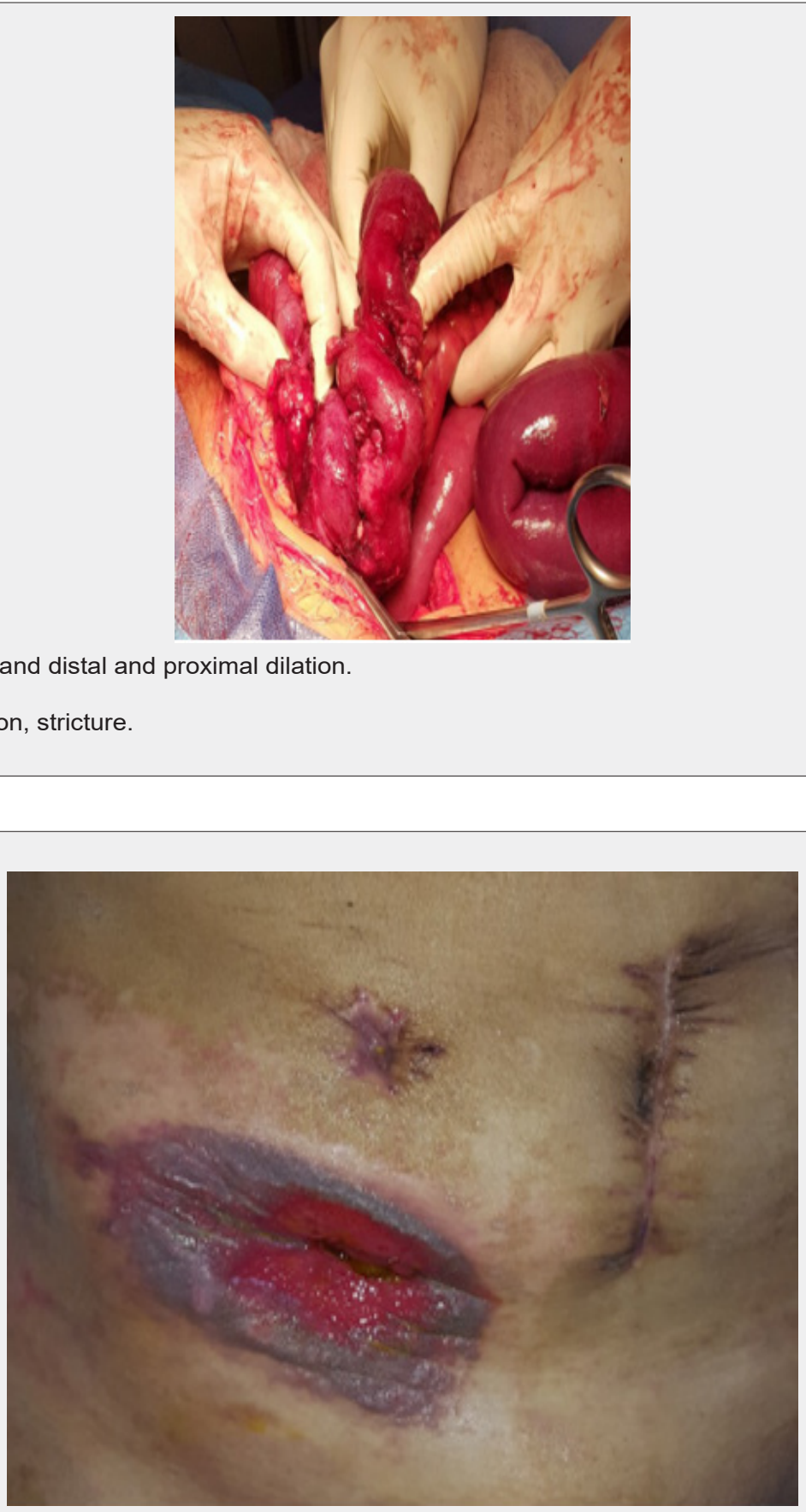

Figure 3: Burn in the right iliac fossa, ileostomy area. 
A third intervention was performed due to dehiscence of the anastomosis suture (high-debit fistula). The management of this complication was drainage of the localized peritonitis, ileostomy, transverse colostomy due to the impossibility of resection and ileocolic anastomosis, lysis of peritoneal adhesions; mixed total parenteral and elemental enteral nutrition, antibiotic therapy according to cultures and sequential antibiotics with Meropenem-Metrodinazole-Vancomycin were started in the ICU.

It should be noted that in the last days of hospitalization, the patient was on elemental enteral feeding and began a progressive oral route, which she tolerates, medical discharge is decided with recommendations, education on wound care and prevention of risk factors.

\section{Discussion}

Appendectomy is a very common procedure today, despite being so common it is not exempt from the complications that every surgical procedure entails and even more so if the intrinsic pathology has evolved to states of greater organic involvement. One of the complications that can occur after an appendectomy is the formation of an appendicular plastron, which is the formation of a type of abdominal adherence secondary to an inflammatory process, this is a strange complication of which there are not very clear statistics of his presentation [12-13].

Continuing with the complications, we found intestinal obstruction with an incidence of $0.2 \%$, this was found in a descriptive, observational and prospective study of 560 appendectomized patients [14], intestinal obstruction is a complication that occurs in various ways, one of which is obstruction due to secondary adhesions, after a surgical procedure [15], in this case the obstruction was secondary to the appendicular stump.

Moving on to another complication, we have the presence of hematoma, a complication in abdominal surgeries, whose incidence is around $0.8 \%$ [16].

Another complication associated with appendicitis is suture dehiscence. The frequency with which it occurs will depend on the surgical technique, the patient's response and the surgical procedure to be performed. Generally, when there is dehiscence it is because the stitches made have produced a tissue tear. Another possible cause of dehiscence will be the excessive tension of the stitches, resulting in strangulation of the edges of the suture, compromising local circulation. Stitches with weak tension, an inappropriate suture technique, or inappropriate suture material for the wound, among others [17] also influence.

\section{References}

1. Andersson REB (2004) Meta-analysis of the clinical and laboratory diagnosis of appendicitis. Br J Surg 91(1): 28-37.

2. Kearney D, Cahill R, O’Brien E, Kirwan W, Redmond H (2008) Influence of delays on perforation risk in adults with acute appendicitis. Dis Colon Rectum 51(12): 1823-1827.

3. Florence M, Flum DR, Jurkovich GJ, Lin P, Steele SR, et al. (2008) Negative appendectomy and imaging accuracy in the Washington State Surgical Care and Outcomes Assessment Program. Ann Surg 248: 557563

4. Shelton T, McKinlay R, Swchwatz RW (2003) Acute appendicitis: Current diagnosis and treatment. Current Surgery 60(5): 502-505.

5. Zinner MJ, Ashley SW (2007) Appendix and Appendectomy, (Chapter 21), Maingot's Abdominal Operations. The McGraw-Hill's Companies, Access surgery, USA.

6. (2007) Apendicitis aguda. T 1, S 2, Enfermedades digestivas. El Manual Merck de diagnóstico y tratamiento. (11 ${ }^{\text {th }}$ edn.), Elsevier España, Madrid, Spain, pp. 108-110.

7. Álvarez R, Bustos A, Torres O, Cancino A (2002) Apendicitis aguda en mayores de 70 años. Rev Chil Cir.54: 345-349.

8. Meier D, Guzzetap, Barber R, Hynan L, Seetharanaiah R (2004) Perforated appendicitis in children: is there a best treatment? J Pediatr Surg 39: 1447.

9. Pittman-Waller VA, Myers JG, Stewart RM et al. (2000) Appendicitis: why so complicated? Analysis of 5755 consecutive appendectomies. Am Surg 66: 548-554.

10. Marques S, Barroso S, Alves O, Magalhaes G, Costa AC, et al. (2007) Risk factors for complications after appendectomy in adults. Rev Bras Coloproctol $27(1)$.

11. Margenthaler JA, Longo WE, Virgo KS, Johnson FE, Oprian CA, et al. (2003) Risk factors for outcomes after the surgical treatment of appendicitis in adults. Ann Surg 238(1): 59-66.

12. María Carolina Berrogain, Noelia González, Silvana Rocha, Cristian Daher, Sergio Moguillansky Apendicitis del muñón apendicular.

13. Baldisserotto M, Cavazzola S, Cavazzolo L, et. al. (2000) Acute Edematous Stump Appendicitis Diagnosed Preoperatively on Sonography, Case Report. AJR 175(2): 503-504.

14. Rodriguez Fernandez Zenén (2010) Complicaciones de la apendicectomía por apendicitis aguda. Rev Cubana Cir 49(2).

15. Manuel Coiiachan La oclusión intestinal mecánica en la apendicitis; Analas de la academia de Barcelona; Sesión científica del 2 de marzo.

16. Silva Sm, Almeida Sb, Lima Oat, Guimarães Gmn, Silva Acc (2007) Factores de riesgo de complicaciones después de apendicetomías en adultos. Rev Bras Coloproct 27(1): 31-36.

17. Luis Del Águila Hoyos, Eugenio Vargas Carbajal, Héctor Angulo Espinoza (1999) Complicaciones Postoperatorias. Tomo I. Cap (26 ${ }^{\text {th }}$ edn.), UNMSM, Lima, Peru. 
This work is licensed under Creative Commons Attribution 4.0 License DOI:10.19080/ARGH.2021.16.555942

\section{Your next submission with JuniperPublishers will reach you the below assets}

- Quality Editorial service

- Swift Peer Review

- Reprints availability

- E-prints Service

- Manuscript Podcast for convenient understanding

- Global attainment for your research

- Manuscript accessibility in different formats

( Pdf, E-pub, Full Text, audio)

- Unceasing customer service

Track the below URL for one-step submission https://juniperpublishers.com/online-submission.php 